\title{
Simplified Building Thermal Model Used for Optimal Control of Radiant Cooling System
}

\author{
Lei He, Bo Lei, Haiquan Bi, and Tao Yu \\ School of Mechanical Engineering, Southwest Jiaotong University, Chengdu 610031, China \\ Correspondence should be addressed to Bo Lei; lbswjtu@163.com
}

Received 10 November 2015; Accepted 26 January 2016

Academic Editor: Hiroyuki Mino

Copyright ( 92016 Lei He et al. This is an open access article distributed under the Creative Commons Attribution License, which permits unrestricted use, distribution, and reproduction in any medium, provided the original work is properly cited.

\begin{abstract}
MPC has the ability to optimize the system operation parameters for energy conservation. Recently, it has been used in HVAC systems for saving energy, but there are very few applications in radiant cooling systems. To implement MPC in buildings with radiant terminals, the predictions of cooling load and thermal environment are indispensable. In this paper, a simplified thermal model is proposed for predicting cooling load and thermal environment in buildings with radiant floor. In this thermal model, the black-box model is introduced to derive the incident solar radiation, while the genetic algorithm is utilized to identify the parameters of the thermal model. In order to further validate this simplified thermal model, simulated results from TRNSYS are compared with those from this model and the deviation is evaluated based on coefficient of variation of root mean square (CV). The results show that the simplified model can predict the operative temperature with a CV lower than $1 \%$ and predict cooling loads with a CV lower than $10 \%$. For the purpose of supervisory control in HVAC systems, this simplified RC thermal model has an acceptable accuracy and can be used for further MPC in buildings with radiation terminals.
\end{abstract}

\section{Introduction}

Model predictive control (MPC) is a powerful control technique, which can be used in both local and supervisory control in HVAC systems. For example, it was employed to control the zone air temperature serving as a local controller of the VAV damper [1]. Yuan and Perez [2] employed MPC to regulate the temperature within the limits and supply adequate fresh air in a VAV system. Most importantly, the superiority of MPC lies in saving energy as a supervisory controller of HVAC systems. Henze et al. [3] used this technique to generate the optimal setpoint of zone air temperature and the optimal charging and discharging profile of thermal storage for energy saving. Široký et al. [4] applied MPC and weather prediction in a building heating system for energy conservation. MPC is an advanced concept for HVAC systems; therefore it has been widely studied in recent years, which can be found in a review carried out by Afram and Janabi-Sharifi [5].

MPC uses a system model to predict the future states of the system. In the model predictive control of the building thermal process, an accurate building thermal model is a precondition, which is used for the calculation of cooling load, diagnosis of building thermal properties, and prediction of indoor thermal comfort. Generally, the model used for calculating the building thermal process can be classified into three categories: physical model, black-box model, and graybox model. Among these three models, the physical model is most widely used, and there are various software tools using the physical model to simulate the heat transfer process, such as DOE-2, HAPE-20, BLAST, TAS, HVACSIM+, TRNSYS, SPARK, and ESP-r [6, 7]. For improving the accuracy, the physical model is generally solved by the impulse response method or the finite difference method. As a result of high order of the method used, physical model has large calculation costs, but it is a detailed method to represent the physical process. By contrast, the black-box model driven by data cannot reflect the physical thermal process, but it is less time-consuming. However, since the black-box model is determined by the sample data for model training, this model gets inaccurate results when the predicting data exceeds the scope of sample data. Combining the advantages of physical model and black-box model, the gray model was developed. This model has the characteristics of fewer calculation costs, less time consumption, and part revelation of the physical 
thermal process [8]. Since the models for MPC have to be less time-consuming, in comparison with the other two models, the simplified gray-box model with lower model order is more suitable for the MPC solution.

As a simplified gray-box model, the lumped parameter model always combines with other models to construct the MPC controller. Hazyuk et al. [9] adopted this model and state space model to construct MPC for intermittent heating buildings. In their study, the results showed that the forecasting error was below $10 \%$. To maximize the MPC performance, both improving the calculation accuracy and reducing the calculation time of lumped parameter model are valid approaches. For improving the calculation accuracy, it is crucial to identify the model parameters. Based on the simplified thermal response model [10], the least square method was used to identify parameters of a solar house [11]. They found that the model parameters had the quality of nonuniqueness and it was unsuitable for evaluating the building thermal performance. However, the model can adjust the parameters using the sample data, so it is suitable for the building energy management system. Gouda et al. [12] used the sequence quadratic programming method to identify the model parameters of various constructions and to compare different order models. The results showed that second-order model balanced the computational accuracy and calculation consumption moderately. The genetic algorithm with data recorded by building management system was employed to identify the RC model parameters in frequency-domain [13, 14]. Based on the time domain and frequency-domain analysis, a method to simplify the RC model was established [15], and this method has higher applicability than the method based on electrical analogy [16]. Besides the real building operation data, the data acquired from the simulation tools can be used to identify the model parameters as well. O'Neill et al. [17] adopted EnergyPlus [18] to test the forecast model consisting of 3R2C and Extended Kalman Filter. Similarly, a cost-effective building thermal model was verified by EnergyPlus [19]. What is more, EnergyPlus and MATLAB were integrated by BCVTB [20] to develop a cooling load prediction model for optimizing HVAC control, and the model parameters were recognized using the data calculated by simulation tool $[21,22]$. The above researches show that the lumped parameter model has a strong ability to forecast the indoor temperature and the cooling load, which is suitable for the MPC. However, for the building equipped with radiant terminals, there are some differences from the building with air-based system. In the building with radiant terminals, the long wave radiation between interior surfaces cannot be neglected and the control variable of indoor environment is usually the operative temperature. What is more, in the building with all-air system, the incident solar radiation on the interior surfaces firstly warms up the construction. Then the cooling load is generated by convective heat exchange. By contrast, the incident solar radiation on the radiant cooling surface is directly absorbed. Due to the above differences, the long wave radiation among the indoor surfaces and the incident solar radiation on the envelope surfaces cannot be calculated by these models and they are incapable of evaluating wall surface temperatures accurately. Based on the above reasons, these models in the literature $[11-13,15,19,21]$ are inapplicable for the MPC in buildings with radiant terminals.

In order to optimize the operation of the air-conditioning system with radiant terminals by MPC technology, this paper presents a prediction model for a building with radiant floor. This model consists of three parts: simplified RC model, black-model, and semiempirical model. The simplified RC model is used to describe the heat transfer process of the building, and the black-box model is used to forecast the incident solar radiation on the envelope surfaces, while the semiempirical model is adopted to calculate the long wave radiation between interior surfaces. The model parameters are recognized by the genetic algorithm, and the sampling data for the recognition is derived from TRNSYS. Finally, the model is used in a case study to predict the indoor operative temperature and the cooling load of both radiant terminals and ventilation system.

\section{Simplified Building Thermal Model}

The RC model adopts different model structures to represent building elements with various heat conduction and thermal storage. In most studies, the optimization method is employed to simplify the RC model and to determine the model parameters. It is verified that the second-order RC model can reduce the calculation time without any compromise of calculation accuracy compared to the higherorder model [11]. Similarly, Gouda et al. [12] proved that the optimized 2nd-order model could simulate both lightweight and heavyweight buildings with the minimal accuracy loss. Thus, the low-order RC model is used to describe the thermal process of building envelope in this paper. The mean radiant temperature is adopted for calculating the long wave radiation between interior wall surfaces, and a black-box model is used to predict the solar radiation on the envelope surfaces.

2.1. Lumped Parameter Model of Envelopes. Both 3R2C model and 2R1C model are adopted to build the thermal network model of the building, as shown in Figure 1. All the enclosure structures are assumed to be connected to the outdoor environment, and the thermal mass such as interior walls and furniture in the room are neglected in the model. Due to the different orientations of the building, solar radiations on the different surfaces are distinct, leading to the different surface temperatures. To accurately calculate the operative temperature, heat transmissions from the external walls and the roof are separately calculated (1)-(4), and the heat storage performance of window (5) is considered by 2R1C model. The radiant surface is calculated as a surface with a constant temperature. The energy balance for indoor air is shown in (6). The heat gains from internal equipment and occupants are calculated in (6):

$$
\begin{aligned}
& g_{1, i} c_{\text {wall }, i} \frac{d T_{\text {wall }, l, i}}{d t}=\frac{T_{\text {wall }, i}-T_{\text {wall }, l, i}}{f_{3, i} R_{\text {wall }, i}}-\frac{T_{\text {wall }, l, i}-T_{\text {wall }, o, i}}{f_{2, i} R_{\text {wall }}}, \\
& g_{2, i} c_{\text {wall }, i} \frac{d T_{\text {wall }, o, i}}{d t}=\frac{T_{\text {wall } l, i}-T_{\text {wall }, o, i}}{f_{2, i} R_{\text {wall }}}-\frac{T_{\text {wall }, o, i}-T_{\text {air }}}{f_{1, i} R_{\text {wall }}} \\
& -q_{\text {wall,rad }, i}+q_{\text {sol, }, \text { }} \text {, }
\end{aligned}
$$




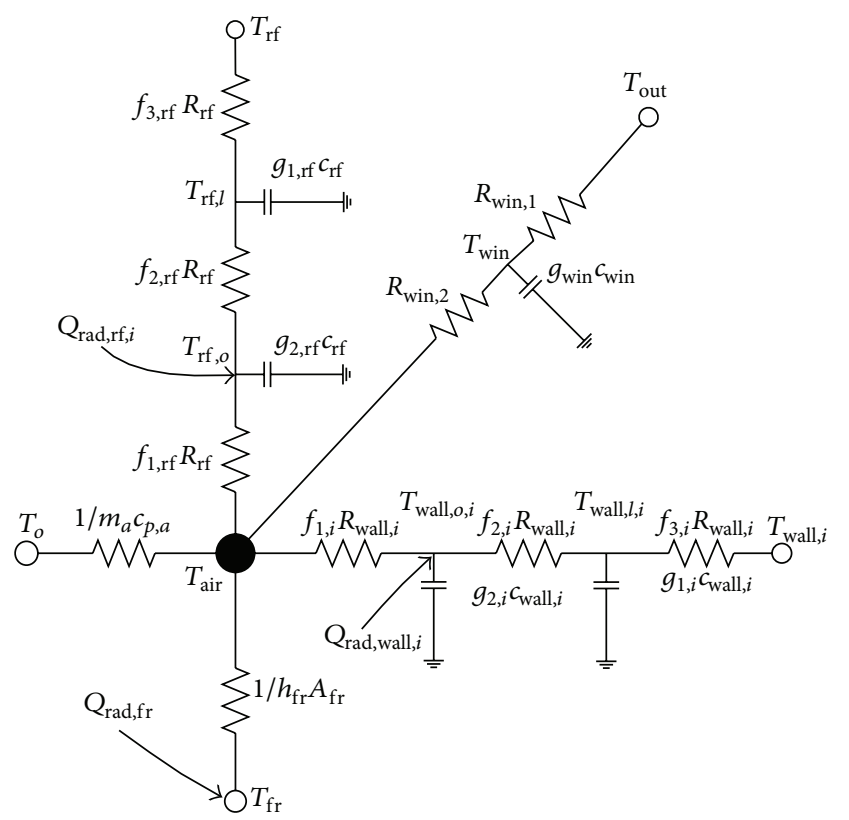

FIGURE 1: Schematic of the simplified building thermal model.

$$
\begin{aligned}
& g_{1, \mathrm{rf}} \mathcal{c}_{\mathrm{rf}} \frac{d T_{\mathrm{rf}, l}}{d t}=\frac{T_{\mathrm{rf}}-T_{\mathrm{rf}, l}}{f_{3, \mathrm{rf}} R_{\mathrm{rf}}}-\frac{T_{\mathrm{rf}, l}-T_{\mathrm{rf}, o}}{f_{2, \mathrm{rf}} R_{\mathrm{rf}}}, \\
& g_{2, \mathrm{rf}} \mathcal{c}_{\mathrm{rf}} \frac{d T_{\mathrm{rf}, o}}{d t}=\frac{T_{\mathrm{rf}, l}-T_{\mathrm{rf}, o}}{f_{2, \mathrm{rf}} R_{\mathrm{rf}}}-\frac{T_{\mathrm{rf}, o}-T_{\mathrm{air}}}{f_{1, \mathrm{rf}} R_{\mathrm{rf}}}-q_{\mathrm{rf}, \mathrm{rad}, i} \\
& +q_{\text {sol,rf }}, \\
& g_{\text {win }} c_{\text {win }} \frac{d T_{\text {win }}}{d t}=\frac{T_{o}-T_{\text {win }}}{R_{\text {win }, 1}}-\frac{T_{\text {win }}-T_{\text {air }}}{R_{\text {win }, 2}}, \\
& \rho V c_{p, \text { air }} \frac{d T_{\text {air }}}{d t}=m_{\text {air }} c_{p, \text { air }}\left(T_{s}-T_{\text {air }}\right) \\
& +\sum_{i=1}^{N=4} A_{\mathrm{wall}, i}\left(\frac{T_{\mathrm{wall}, o, i}-T_{\mathrm{air}}}{f_{1, i} R_{i}}\right) \\
& +A_{\mathrm{fr}}\left(\frac{T_{\mathrm{rf}, o}-T_{\mathrm{air}}}{f_{1, \mathrm{rf}} R_{\mathrm{rf}}}\right) \\
& +A_{\text {win }}\left(\frac{T_{\text {win }, o}-T_{\text {air }}}{R_{\text {win }, 1}}\right) \\
& +h_{\mathrm{fr}} A_{\mathrm{fr}}\left(T_{\mathrm{fr}}-T_{\mathrm{air}}\right)+S \text {. }
\end{aligned}
$$

2.2. Long Wave Radiation Model. In the building equipped with radiant terminals, on one hand, due to the large temperature difference between the radiant surface and interior surfaces, there is long wave radiation heat exchange between radiant terminals and interior surfaces. On the other hand, because of the solar radiation on different interior surfaces, there are temperature differences between the inside envelope surfaces. Therefore, interior surfaces have long wave radiation heat exchange among each other.
The radiant heat transfer between interior surfaces is calculated with the mean radiant temperature based on the balance method of Walton [23]. The model calculates the long wave radiation from one surface to the other surfaces with a fictitious surface temperature which is a weighted average value of other surfaces temperatures, as shown in (7)-(9). The shape factors of every surface to the fictitious surface are calculated by (10), so the long wave radiation can be derived in (11). Because of less calculation, this model is suitable for the model predictive controller:

$$
\begin{aligned}
A_{m r t, i} & =\sum_{\substack{j=1 \\
j \neq i}}^{N} A_{j}, \\
\varepsilon_{m r t, i} & =\frac{1}{A_{m r t, i}} \times \sum_{\substack{j=1 \\
j \neq i}}^{N} A_{j} \varepsilon_{j}, \\
T_{m r t, i} & =\frac{1}{A_{m r t, i} \varepsilon_{m r t, i}} \times \sum_{\substack{j=1 \\
j \neq i}}^{N} A_{j} \varepsilon_{j} T_{\mathrm{wall}, j}, \\
F_{m r t, i} & =\frac{1}{\left(\varepsilon_{m r t, i} / \varepsilon_{i}\right)+\left(A_{i}\left(1-\varepsilon_{m r t, i}\right) / A_{m r t, i}\right)}, \\
q_{\mathrm{rad}, \mathrm{wall}, i} & =\sigma \varepsilon_{m r t, i} F_{m r t, i}\left(T_{\mathrm{wall}, o, i}^{4}-T_{m r t, i}^{4}\right) .
\end{aligned}
$$

2.3. Prediction Model of Solar Radiation Heat Gain. Solar radiation on the outside surface of wall or window will increase the surface temperatures, generating the heat flux through the wall or the window. This heat flux was not considered in some researches $[13,15]$, and the ambient air temperature was used as the boundary condition of outside wall or window. But for a building with radiant terminals, in order to forecast the indoor environment and radiant cooling load, it is necessary to take the solar radiation into consideration. Cooling capacity of the radiant system is primarily affected by the cooling load type [24]. The convective heat transfer accounts for a small proportion of the cooling capacity when the mean surface temperature of radiant terminals is close to the air temperature. The long wave radiation and incident solar radiation are the dominant heat gains removed by radiant terminals. Thus, a perfect prediction of the solar radiation (both direct and diffuse radiation) is important for calculating the cooling load of the radiant terminals. For this reason, both long wave radiation and solar radiation are demanded to be accurate. Thus, the integration temperature [25] converted by the sun radiation and ambient temperature is used as the boundary condition for the exterior wall, which is shown in (12) and can be used for both wall $\left(T_{\text {wall, } i}\right)$ and roof $\left(T_{\mathrm{rf}}\right)$ equations. For the window, because the transmissivity of glass is largely greater than absorptivity, the outside surface temperature of window is unaffected by the incident solar radiation. Hence, the ambient temperature $\left(T_{\text {out }}\right)$ is adopted as the boundary condition of the window:

$$
T_{\text {wall } / \mathrm{rf}, i}=T_{\text {out }}+\frac{\gamma_{i} J_{i}}{h_{i}}
$$




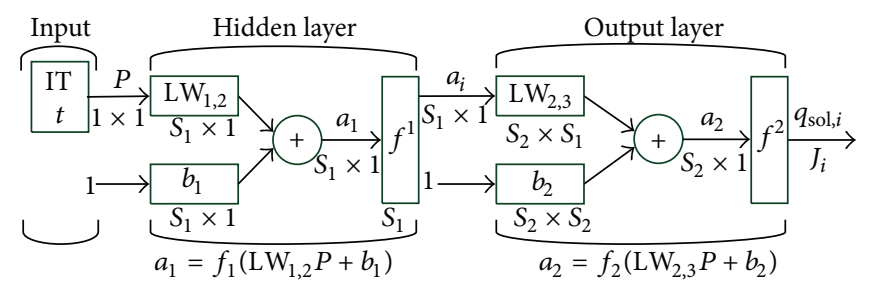

FIGURE 2: Structure chart of BP neural model for incident solar radiation.

On the other hand, direct solar radiation is one of the affecting factors for the surface temperatures, and the temperatures of interior surfaces are the most important factors for the indoor long wave radiation load supplied by radiant terminals. Therefore, it is important to forecast the direct solar radiation on the inside surface for the long wave radiation calculation. For the above reasons, both incident solar radiations on the inside and outside surface of envelopes are significant for the load forecasting model. Incident solar radiations on the envelope surfaces $\left(q_{\text {sol }}, J_{i}\right)$ are influenced by a lot of factors, such as solar azimuth, solar altitude, intensity, building orientation, and envelope surface absorptivity. However, for existing buildings with the known orientation and envelope surface absorptivity, solar radiation on the envelope surface is only a function of the solar azimuth, altitude, and intensity. Solar radiation physical model [26] can predict the solar radiation on the various orientation building surfaces. However, direct solar radiation on the inside envelope surfaces is influenced by many factors that are not considered in the physical model, involving the window orientation, area, and glass transmissivity. Therefore, it is difficult to determine the short wave radiation on the inside envelope surfaces. Moreover, due to the shading effect of other buildings and shading devices, the incidental solar radiation on the block cannot be accurately calculated. Thus, it is an effective way to build a forecast model based on the measurement data to predict the radiation in order to avoid the uncertainties.

In this study, the black-box model driven by data is used for building the prediction models for solar radiation on both inside and outside envelope surfaces $\left(q_{\text {sol }}, J_{i}\right)$. Through analyzing the sample data, the black-box model can express the regulation between the input data and output data. Then the regulation can be used for predicting unknown results by the input data [27]. As a frequently used black-box model [28], back propagation neural network has a lot of advantages, such as self-adaptation and powerful ability to deal the noisy data and missing data [28]. Hence, BP neural network with two layers is adopted to identify the regulation between the solar radiation on various envelope surfaces and the horizontal incident solar radiation, as shown in (13)-(14). The incident solar radiation on the horizontal plane and the time in 24-hour time system are used to calculate the heat gains of incident solar radiation on the outside surfaces and the short wave radiation on the inside surfaces. The structure of the neural network is shown in Figure 2. This mode from the input layer to the output layer has the characteristics of nonlinear mapping and the ability to avoid the local minimum problem. There are 20 neurons in the hidden layer, and the output layer is the weighted sum of hidden layer. The sigmoid function and linear function are used for the hidden layer and the output layer, respectively:

$$
\begin{aligned}
q_{\mathrm{sol}, i} & =f(\mathrm{IT}, t), \\
J_{i} & =f(\mathrm{IT}, t) .
\end{aligned}
$$

\section{Identification Method of Model Parameters}

The model identification is a method to determine a model to describe the test system based on the input and output data. In general, the model identification method can be classified into two categories: with and without the reference model. Since the model identification method with the reference model is intelligible and flexible, it is adopted to build the prediction model for the indoor environment and cooling load. Meanwhile, the hybrid model as shown in Section 2 is employed as the reference model. The reference model is used for calculating the results of the sample data. Then the model parameters are adjusted to reduce the difference between results of reference model and the actual value of sample data. Repeat this process until the difference can be acceptable. Finally, the parameters getting the acceptable difference can serve as the predicting model parameters. As described in Section 2, there are six unknown parameters $\{g, c, f, R, \gamma, h\}$ in the RC model.

The output of the RC model, such as the inside envelope surface temperatures, indoor temperature, and cooling load removed by radiation system and ventilation system, are used for building the objection function, as shown in (15). It consists of the differences between actual value and the output data of the predicting model:

$$
\begin{aligned}
& \text { fitness }=\sum_{i=1}^{N}\left(\omega_{i}\left(T_{\text {wall }, i}(t)-\bar{T}_{\text {wall }, i}(t)\right)^{2}\right. \\
& +\omega_{\mathrm{rf}}\left(T_{\mathrm{rf}}(t)-\bar{T}_{\mathrm{rf}}(t)\right)^{2} \\
& +\omega_{\text {win }}\left(T_{\text {win }}(t)-\bar{T}_{\mathrm{win}}(t)\right)^{2} \\
& +\omega_{\text {air }}\left(T_{\text {air }}(t)-\bar{T}_{\text {air }}(t)\right)^{2} \\
& +\omega_{\mathrm{Q}_{\mathrm{air}}}\left(\mathrm{Q}_{\mathrm{air}}(t)-\overline{\mathrm{Q}}_{\mathrm{air}}(t)\right)^{2} \\
& \left.+\omega_{\mathrm{Q}_{\mathrm{fr}}}\left(Q_{\mathrm{fr}}(t)-\overline{\mathrm{Q}}_{\mathrm{fr}}(t)\right)^{2}\right)
\end{aligned}
$$




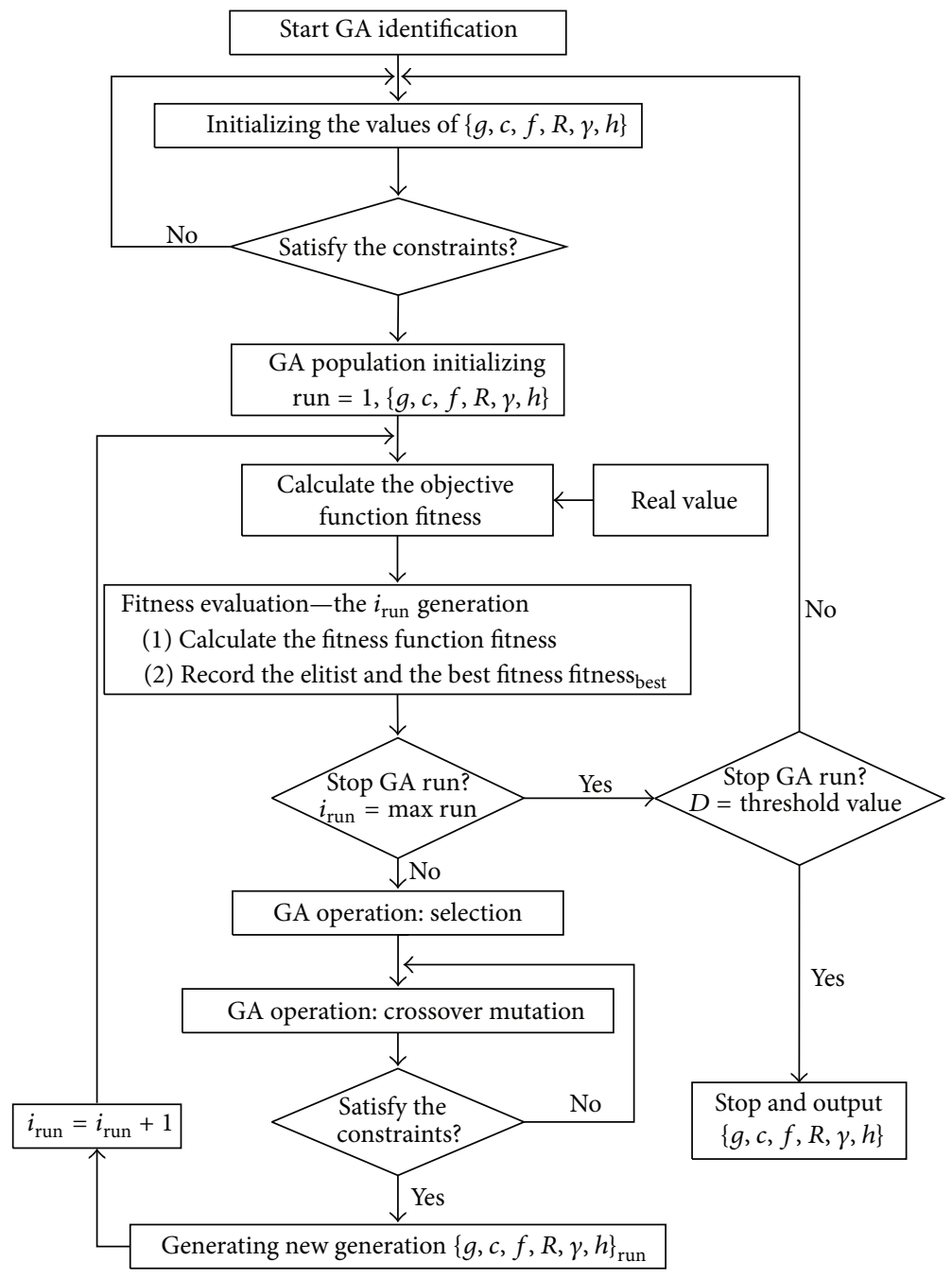

FIGURE 3: Identification method for model parameters.

$$
\begin{aligned}
& \omega_{\mathrm{rf}}+\sum_{i=1}^{N} \omega_{\mathrm{wall}, i}+\omega_{\mathrm{air}}+\omega_{\mathrm{win}}+\omega_{\mathrm{Q}_{\mathrm{air}}}+\omega_{\mathrm{Q}_{\mathrm{fr}}}=1, \\
& \omega_{\mathrm{rf}}, \omega_{\mathrm{wall}, i}, \omega_{\mathrm{air}}, \omega_{\mathrm{win}}, \omega_{\mathrm{Q}_{\mathrm{air}}}, \omega_{\mathrm{Q}_{\mathrm{fr}}} \geq 0
\end{aligned}
$$

where fitness, $Q_{\text {air }}(t)$, and $Q_{\mathrm{fr}}(t)$ are the objection function, cooling load of radiation system, and ventilation system, respectively. The cooling load of radiation system is defined as the heat transfer (combined radiant and convective) at the radiant surface. The cooling load of ventilation system is defined as convective heat removed by the ventilation air. According to the demand of multiobjective optimization, all the weight factors $\omega$ have to satisfy the conditions in (16) and (17).

To get the model parameters, it is crucial to solve the optimization problem in (15) with the specified conditions in (16) and (17). Since the model is complicated and there are many model parameters, the genetic algorithm independent of the gradient of optimization function is employed to solve the problem. In order to accelerate the calculation and ensure the physical meaning for the model parameters, these unknown parameters are determined within a range as given in (18). These unknown parameters of the model are compiled into the individual chromosomes, which are used for calculating the objection function. Through comparing the objection function values, these individuals with biggish objection function value are selected to create the new generation through the crossover and mutation operation. Then the objection function is evaluated again by the new generation. The GA solver will stop when the relative difference between the objection function values of two generations is acceptable or reaches the maximum generations, as shown in Figure 3. Finally, the individual with the best fitness value is selected as the model parameter:

$$
\begin{aligned}
0.01 & \leq R_{i} \leq 20, \\
1 \times 10^{4} & \leq c_{\text {wall }, i} \leq 1 \times 10^{7}, \\
10 & \leq c_{\text {win }} \leq 1 \times 10^{3}, \\
0 & \leq \gamma_{i} \leq 1, \\
1 & \leq h_{i} \leq 30,
\end{aligned}
$$


TABLE 1: Construction element properties.

\begin{tabular}{lccccc}
\hline Element & Layers & Thickness $[\mathrm{m}]$ & $\begin{array}{c}\text { Thermal conductivity } \\
{[\mathrm{W} /(\mathrm{m} \cdot \mathrm{K})]}\end{array}$ & $\begin{array}{c}\text { Specific heat } \\
\text { capacity }[\mathrm{J} /(\mathrm{kg} \cdot \mathrm{K})]\end{array}$ & $\begin{array}{c}\text { Density } \\
{\left[\mathrm{kg} / \mathrm{m}^{3}\right]}\end{array}$ \\
\hline \multirow{3}{*}{ External wall } & Brick & 0.24 & 0.89 & 1000 & 800 \\
& Insulation & 0.1 & 0.04 & 1800 \\
& Plaster & 0.015 & 1.39 & 1000 & 2000 \\
\hline \multirow{2}{*}{ Roof } & Concrete & 0.24 & 2.10 & 800 & 800 \\
& Insulation & 0.16 & 0.04 & $T_{\text {sol }}$-value 0.83 \\
\hline Window & & $U$-value 2.27 & & 40 \\
\hline
\end{tabular}

$$
\begin{aligned}
& \sum_{i=1}^{3} f_{i}=1 \\
& \sum_{i=1}^{2} g_{i}=1 .
\end{aligned}
$$

\section{Case Study}

In the inhabited buildings, the occupants' activity has an influence on the accurately measuring of envelope cooling load and the solar radiation. Instead of a real building a virtual building is used to test the model identification method in this paper.

4.1. Testing Case. Simulation tools are convenient to get the sample data for model identification. Therefore, the simulation tool-TRNSYS-is selected to generate the sample data for testing the identification method, and the following conditions are assumed.

(1) The building thermal performance is stable in the identification period.

(2) The convective heat transfer coefficients of envelope surfaces are not affected by air velocity and air temperature.

(3) The radiant floor is assumed to have the uniform and constant temperature. Since the purpose of this model is to predict the effect of radiant terminal temperature on the thermal environment and cooling load of system, the detailed thermal process of radiant floor with circulating water is not considered.

The simulated case is depicted in Figure 4, and the dimension of this reference room is $4.9 \mathrm{~m}$ (length) $\times 2.7 \mathrm{~m}$ (width) $\times$ $4.8 \mathrm{~m}$ (height). One window with a dimension of $2.0 \mathrm{~m}$ (width) $\times 3.0 \mathrm{~m}$ (height) is located in the south wall, and the percentage of glazed area compared to the south wall area is $46.3 \%$. The convective heat transfer coefficients of surfaces are determined according to EN ISO 15255 [29]. Thermal properties of the constructions are listed in Table 1. The internal heat sources involve two occupants and two computers, with the total power of $580 \mathrm{~W}$, and the daily operation profile is depicted in Figure 5. The indoor thermal environment of this building is controlled by both cooling floor and ventilation system.

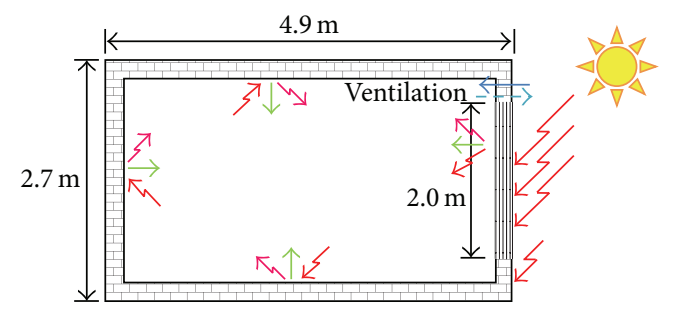

$$
\begin{aligned}
& \rightarrow \text { Incident solar radiation } \\
& \rightarrow \text { Long wave radiation } \\
& \rightarrow \text { Convection }
\end{aligned}
$$

Figure 4: Geometry of the building for testing case.

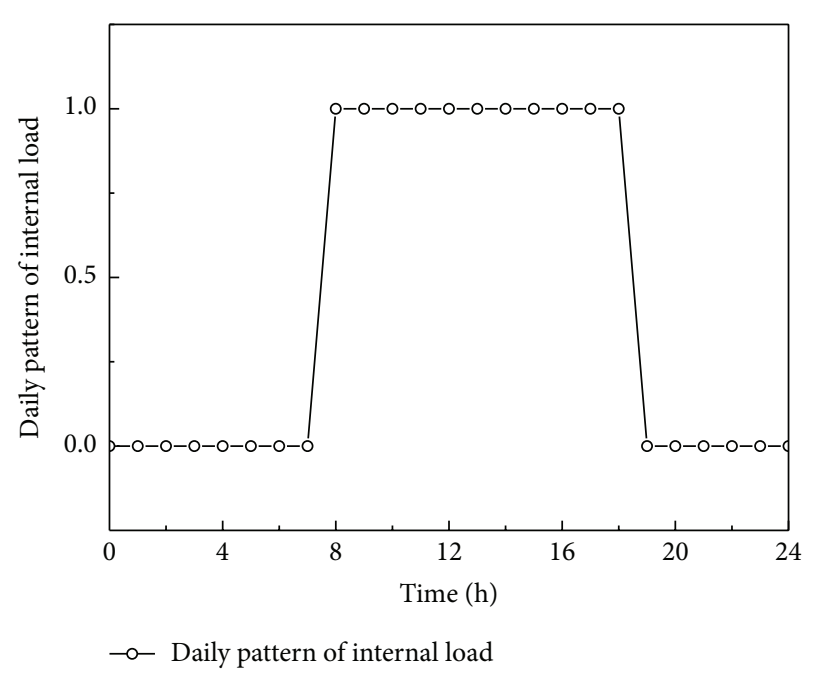

FIGURE 5: Normal patterns of internal load.

4.2. Solar Radiation on Envelop Surfaces. In order to identify the parameters of the model, the solar radiation on the envelope surfaces has to be identified firstly. The data calculated by the TRNSYS simulation tool, including horizontal solar radiation, time, short wave radiation on inside surfaces, and incident solar radiation on outside surfaces, is used for training the black-box model. The sample data of solar radiation during one week is shown in Figure 6. Obviously, the intensities of solar radiation on all surfaces are basically proportional to the horizontal solar radiation (IT). The short wave radiation on the floor is larger than those on the other 
TABLE 2: CV of predicted values for incident solar radiation.

\begin{tabular}{lcccccc}
\hline & South wall & North wall & West wall & East wall & Roof & Floor \\
\hline Inside & - & - & $9.66 \%$ & $9.23 \%$ & - & $8.67 \%$ \\
Outside & $7.22 \%$ & $9.79 \%$ & $13.23 \%$ & $12.16 \%$ & $0.67 \%$ & - \\
\hline
\end{tabular}

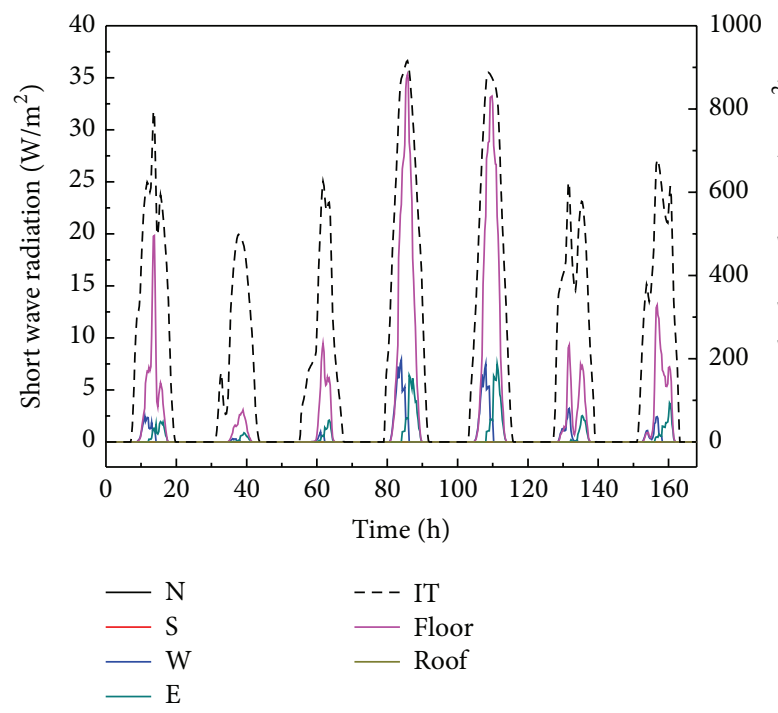

(a) Short wave radiation on the inside envelope surfaces

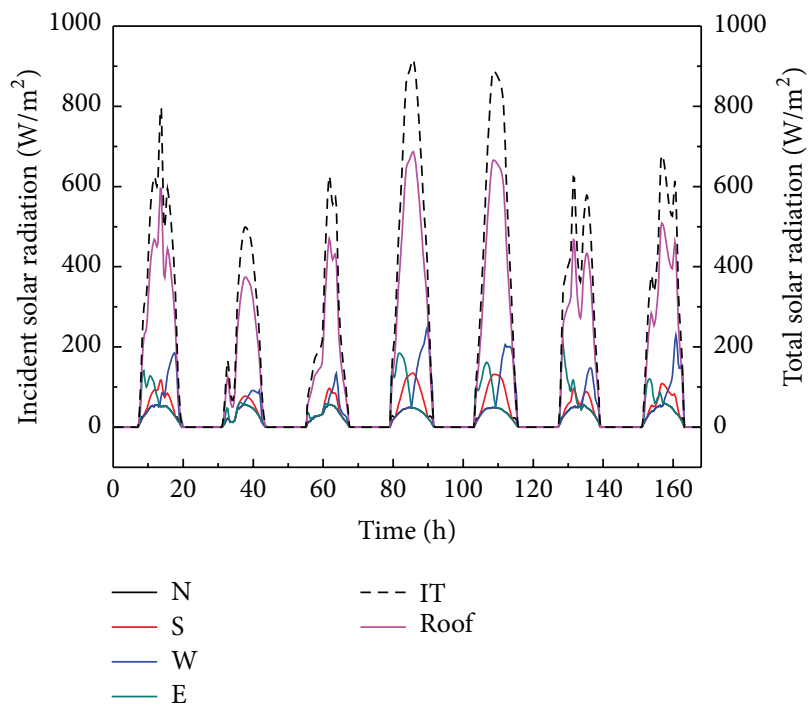

(b) Incident solar radiation on the outside envelope surfaces

FIGURE 6: Sample data of solar radiation of surfaces and horizontal solar radiation.

inside surfaces. Because the short wave radiation cannot reach the inside surface of north wall, south wall, and roof, the short wave radiation of them is zero. Moreover, the outside surface of east wall has the larger solar radiation in the forenoon. By contrast, the west wall has the larger solar radiation in the afternoon. Since there is no incident solar radiation in the night, the radiation heat fluxes of all surfaces are zero.

The data of incident solar radiation and solar heat gains for all envelope surfaces within one month are used as the sample data for building the black-box model. For improving the prediction accuracy of the incident solar and model training speed, the sample data is normalized to a range of 0 to 1 in the preprocessing. The sample data is randomly divided into two groups, training sample and testing sample. The training sample is used for building the prediction model for the solar heat gains on the envelope, while the testing sample is used for validation. The predicted values of solar radiation heat gain on the inside surfaces and outside surfaces by the model and the actual value of sample data are shown in Figure 7. It can be seen that the model has the same prediction accuracy for the training data and testing data. Moreover, comparing Figures 7(a) and 7(b), because of the influence of the window structure and glass transmissivity, it is very clear that the solar heat gains of inside surfaces are far less than those of outside envelope surfaces.

The coefficient of variation of root mean square $(\mathrm{CV})$ as given in (19) has the ability to test the average deviation between the predicted value and the actual value, which is not affected by the sample data size. For this reason, the CV value is adopted to test the model performance for estimating the solar heat gain:

$$
\mathrm{CV}=\frac{\sqrt{\sum_{i=1}^{n}\left(y_{i}-\widehat{y}_{i}\right)^{2} / n}}{\left|\bar{y}_{i}\right|}
$$

where $y_{i}, \bar{y}_{i}, \widehat{y}_{i}$, and $n$ are sample data actual value, average value of sample data, predicted value by the model, and sample data amount, respectively.

The CV values of the solar radiation heat gains on both side surfaces of envelopes are calculated to evaluate the prediction model with the test sample, which is presented in Table 2. The prediction model is enough accurate to forecast the solar radiation heat gain of envelope inside surfaces, with all $\mathrm{CV}$ values being below $10 \%$. But the adaptability of the prediction model for the outside surfaces facing east and west is poor, and the CV values are greater than $10 \%$. Because the solar radiation on the outside envelope-surfaces has a small effect on the building cooling load, the errors of prediction value are acceptable. So the black-box model is considered to be reliable for the prediction of solar radiation heat gains. Accordingly, it is used in the RC model to forecast the solar radiation heat gains of envelope surfaces $\left(q_{\text {sol }}\right.$ and $\left.J_{i}\right)$.

4.3. Data for Identification. The simulation process is influenced by the initial conditions, and a duration called "warmup" is needed to eliminate the influence of the initial conditions on the simulation results. As depicted in Figure 8, there are seven cases with different "warm-up" durations 


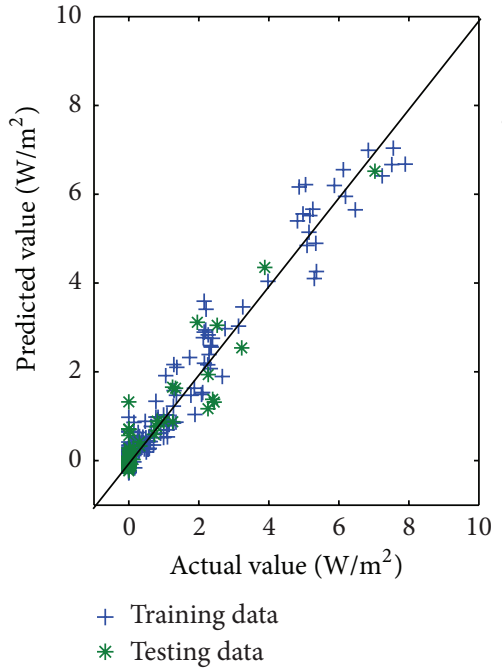

(A) West wall

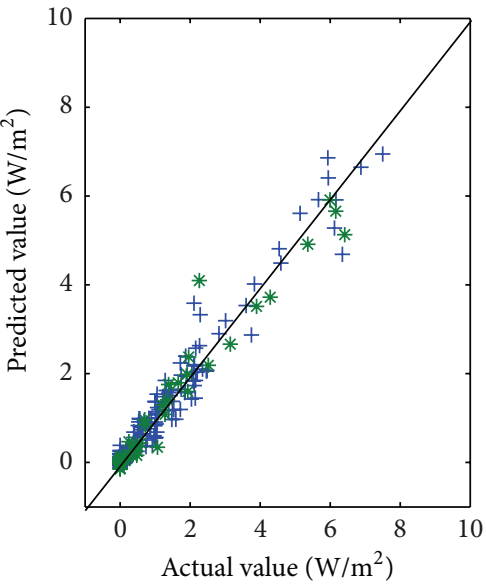

+ Training data

* Testing data

(B) East wall

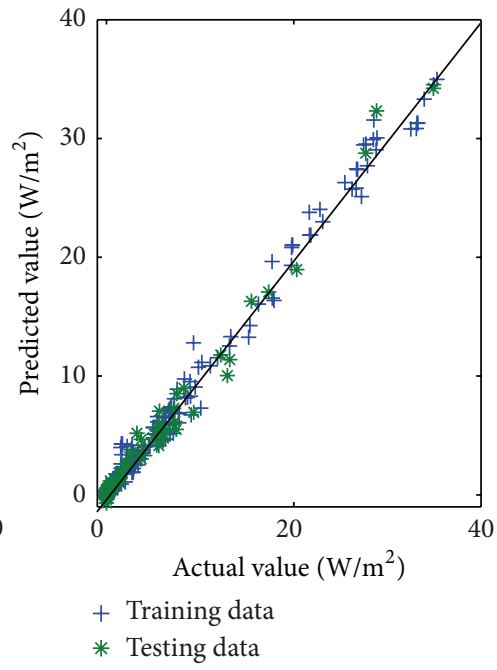

(C) Floor

(a) Short wave radiation on the inside surfaces

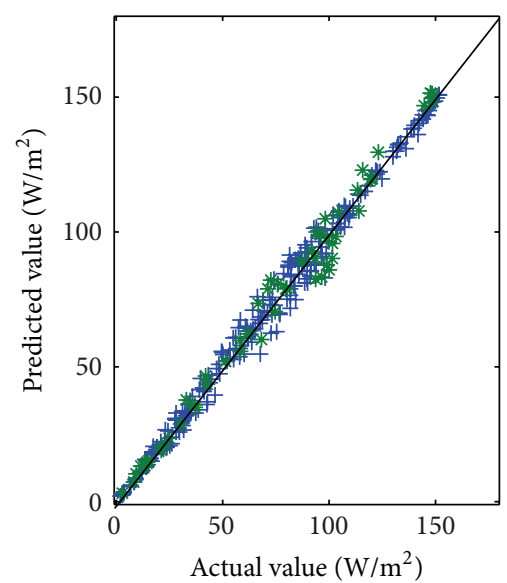

(A) South wall

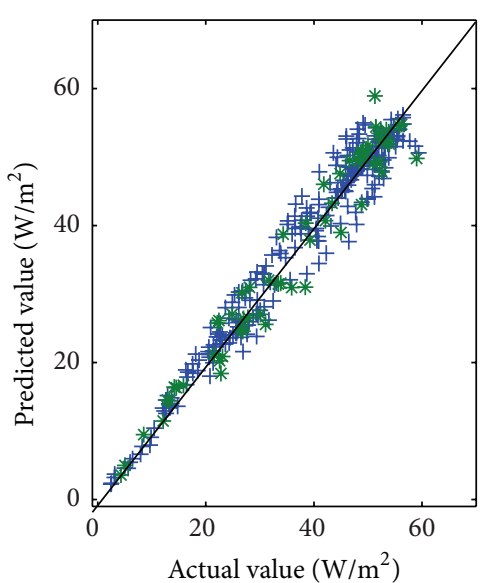

(B) North wall

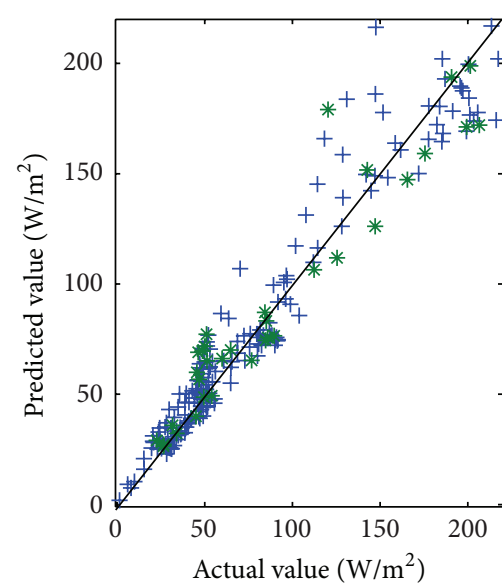

(C) West wall

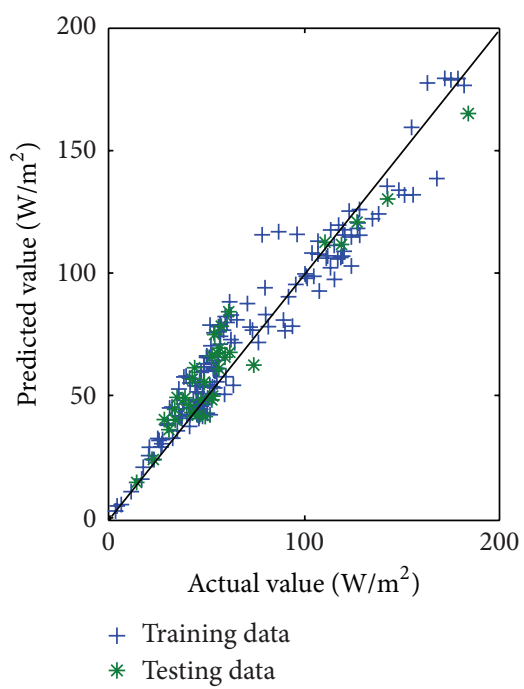

(D) East wall

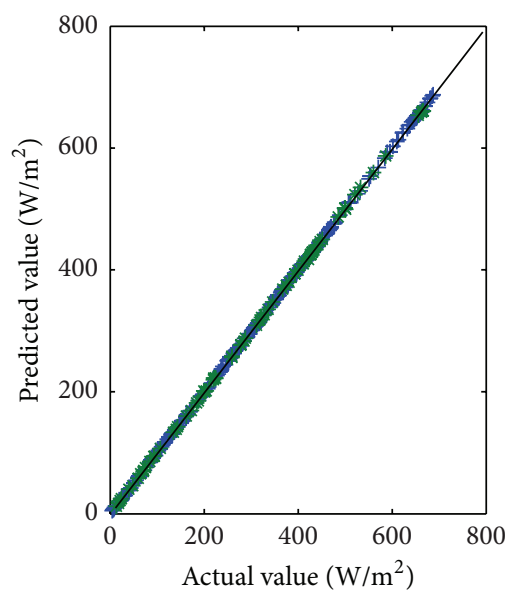

+ Training data

* Testing data

(b) Solar radiation (direct radiation and diffusion radiation) on the outside surfaces

FIGURE 7: BP model predicted value versus actual value of solar radiation. 


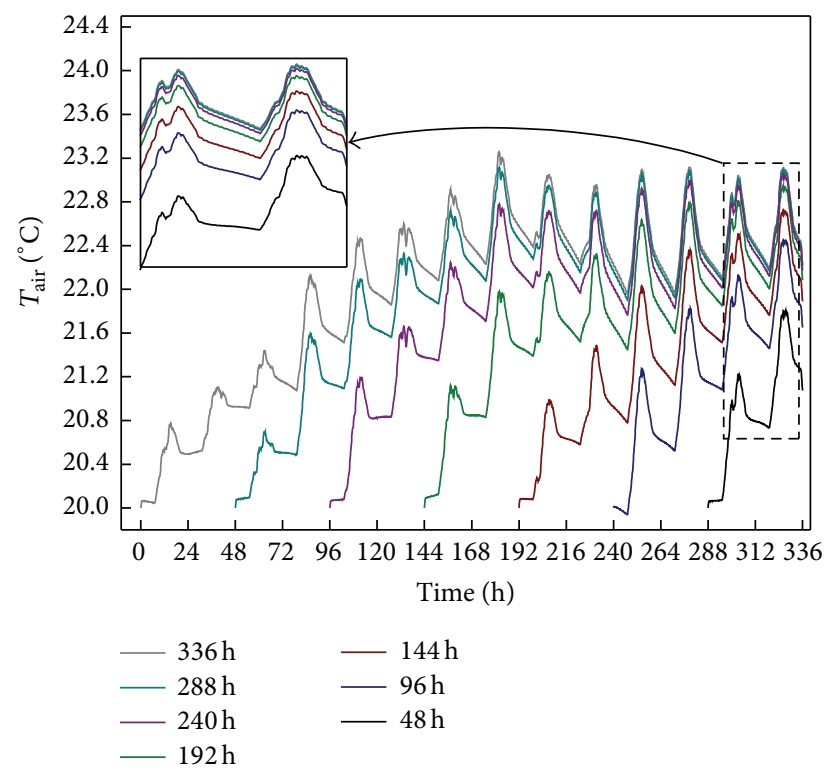

FIGURE 8: Schematic diagram for warm-up period of simulation case.

from 2 days to 14 days. All cases are started at the same initial conditions with the same ambient environment. Due to the different "warm-up" durations, it is obvious that the indoor temperatures of different cases are different. After the "warmup" duration, the calculation results will not be affected by the initial conditions. According to Figure 8, in the last day, the indoor temperatures have no difference between 12 days and 14 days. It shows that the simulation case can avoid the influence of initial conditions through a transitional period of 14 days. In order to ensure the identification accuracy of model parameters, the simulation data during the "warm-up" process are not included in the sample data. After the 14-day "warm-up" process, the simulation results within 4 days are used for identifying the simplified model.

\section{Results and Discussions}

For the model predictive control of the ventilation system combining radiant terminals and air system, accurate forecasting results of both indoor air temperature and temperatures of envelope surfaces are crucial. In order to apply the model in MPC, all the envelope parameters have to be amenable for different ambient conditions and system status. For this reason, the meteorological parameters depicted in Figure 9 are employed to test the reliability of the identification method and the prediction model.

Since the operative temperature as described in (20) can represent the effect of air temperature and envelope temperature on the indoor environment, it is used for testing the model in terms of cooling load of air system and radiant cooling floor:

$$
\begin{aligned}
& t_{o}=a_{r} \overline{t_{r}}+\left(1-a_{r}\right) t_{\mathrm{air}}, \\
& \overline{t_{r}}=\frac{\left(0.08\left(t_{\mathrm{rf}}+t_{\mathrm{fr}}\right)+0.23\left(t_{w}+t_{e}\right)+0.35\left(t_{s}+t_{n}\right)\right)}{(2 \times(0.08+0.23+0.35))},
\end{aligned}
$$

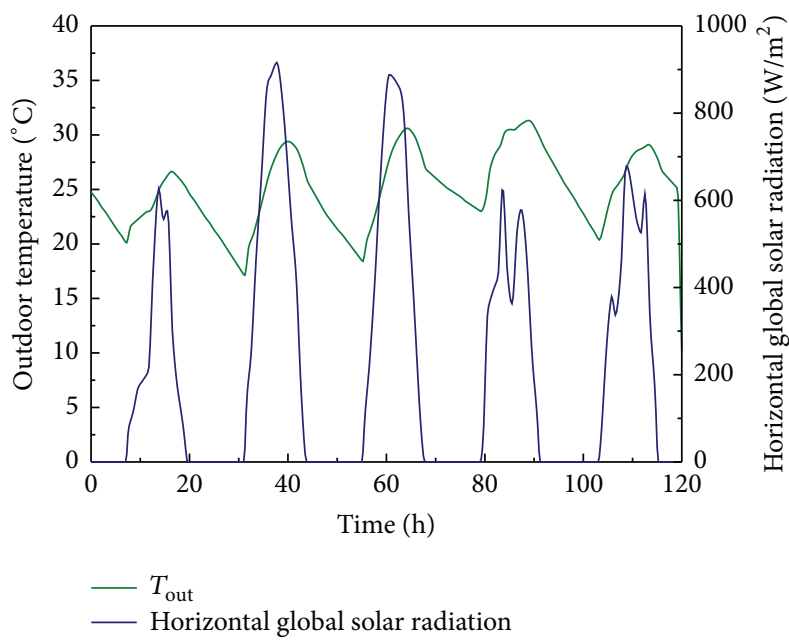

FIGURE 9: Ambient temperature and horizontal global solar radiation.

$$
t_{s}=\frac{A_{s} t_{\text {wall }, s}+A_{\text {win }} t_{\text {win }}}{A_{s}+A_{\text {win }}},
$$

where $\bar{t}_{r}$ is the mean radiant temperature and $a_{r}$ is the radiant fraction. $a_{r}$ is a function of relative velocity recommended by international standard ISO 7730 [30]. Because the indoor air velocity is usually below $0.2 \mathrm{~m} / \mathrm{s}$, it is assumed to be 0.5. The mean radiant temperature $\overline{t_{r}}$ which is used for a standing person [31] can be calculated with (21). Since there is a window on the south surface of envelope, the south surface temperature $t_{s}$ is calculated by the area-weight average temperature of window surface and wall surface (22). The simplified thermal model for radiant system is tested by TRNSYS and the testing results with various floor temperatures, air volumes, and supply air temperatures are shown in Figures 10-12.

5.1. Effect of Floor Temperature. Figure 10 shows the effect of floor temperature on the operative temperature and the cooling load when the supply air temperature is $18^{\circ} \mathrm{C}$ with an air change rate of $1 \mathrm{~h}^{-1}$. As seen in Figure 10, with the same other conditions, both operative temperature and cooling load of air system increase with the floor surface temperature, while the cooling load supplied by the floor decreases. The operative temperature deviations between the simplified model and TRNSYS are less than $0.26^{\circ} \mathrm{C}$. Meanwhile, the floor cooling load deviations are less than $6.9 \mathrm{~W} / \mathrm{m}^{2}$ and the cooling load deviations of ventilation system are less than $0.9 \mathrm{~W} / \mathrm{m}^{2}$.

5.2. Effect of Air Change Rate. Similarly, Figure 11 presents the effect of air change rate when the supply air temperature is $18^{\circ} \mathrm{C}$ and floor temperature is $19^{\circ} \mathrm{C}$. As shown in Figure 11, with the same other conditions, both operative temperature and cooling load supplied by the floor decrease with the increase of air change rate, while the cooling load of air system increases significantly. In this case, the deviations of 


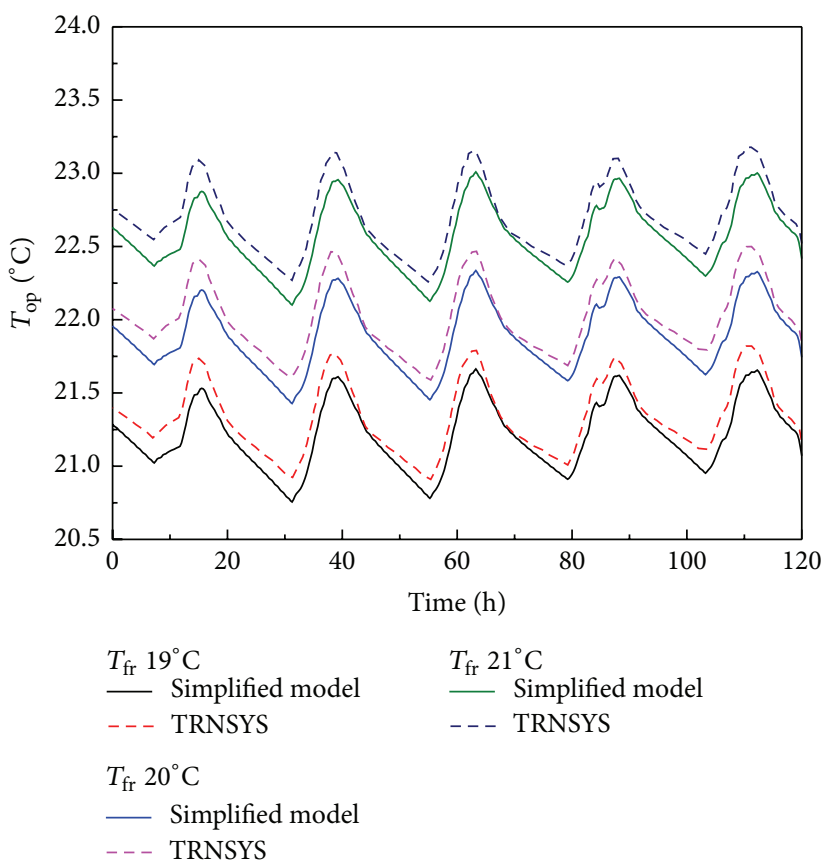

(a) Operative temperature

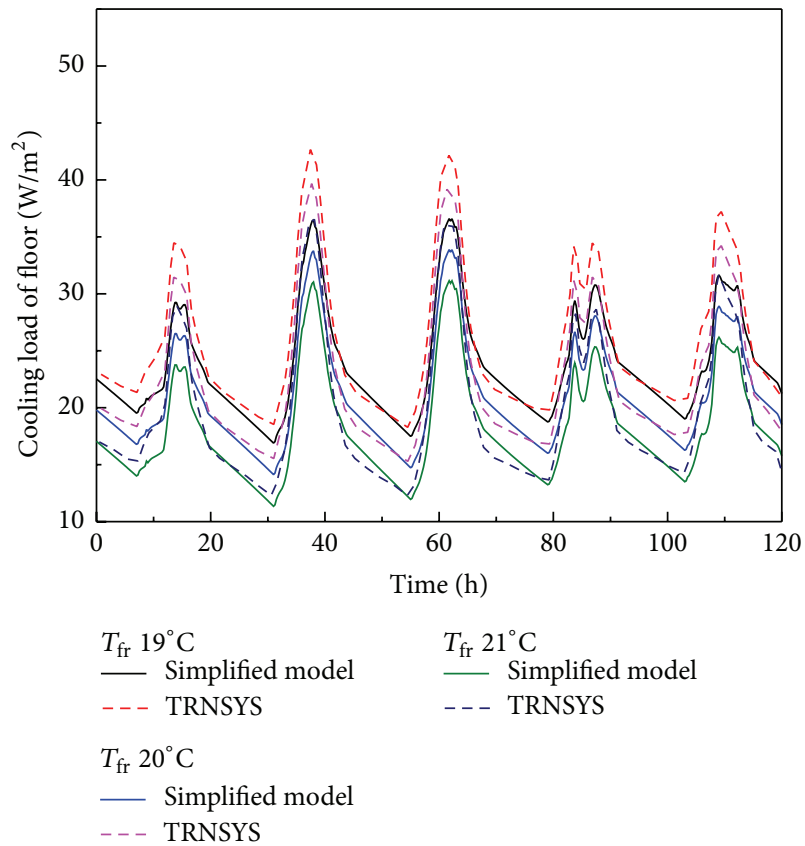

(b) Cooling load of floor

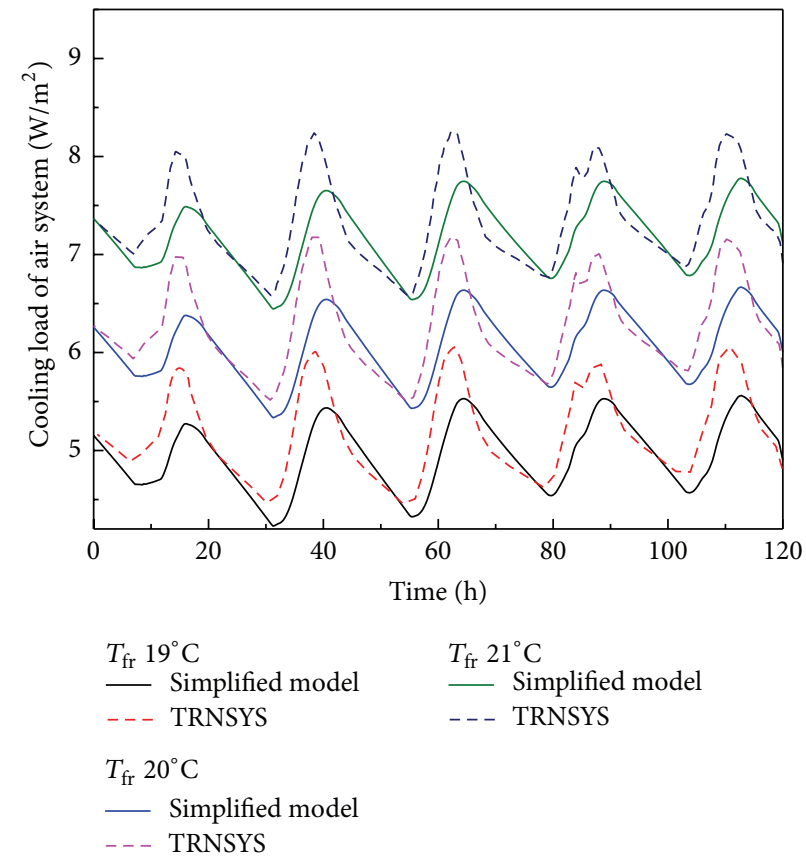

(c) Cooling load of ventilation system

Figure 10: Results of simplified model and TRNSYS with various $T_{\mathrm{fr}}\left(\mathrm{ACH}=1\right.$ and $\left.T_{s}=18^{\circ} \mathrm{C}\right)$.

operative temperature, floor cooling load, and ventilation system cooling load are less than $0.25^{\circ} \mathrm{C}, 6.9 \mathrm{~W} / \mathrm{m}^{2}$, and $1.9 \mathrm{~W} /$ $\mathrm{m}^{2}$, respectively.

5.3. Effect of Supply Air Temperature. Figure 12 describes the effect of various supply air temperature with an air change rate of $1 \mathrm{~h}^{-1}$ and floor temperature of $19^{\circ} \mathrm{C}$. In Figure 12, with the same other conditions, the operative temperature increases with the supply air temperature. Meanwhile, the cooling load supplied by the floor decreases slightly. Besides, the cooling load of air system significantly increases with the fall of supply air temperature. The operative temperature deviations between the simplified model and TRNSYS are less than $0.25^{\circ} \mathrm{C}$. Meanwhile, the floor cooling load deviations are less than $6.9 \mathrm{~W} / \mathrm{m}^{2}$ and the cooling load deviations of ventilation system are less than $0.9 \mathrm{~W} / \mathrm{m}^{2}$. 

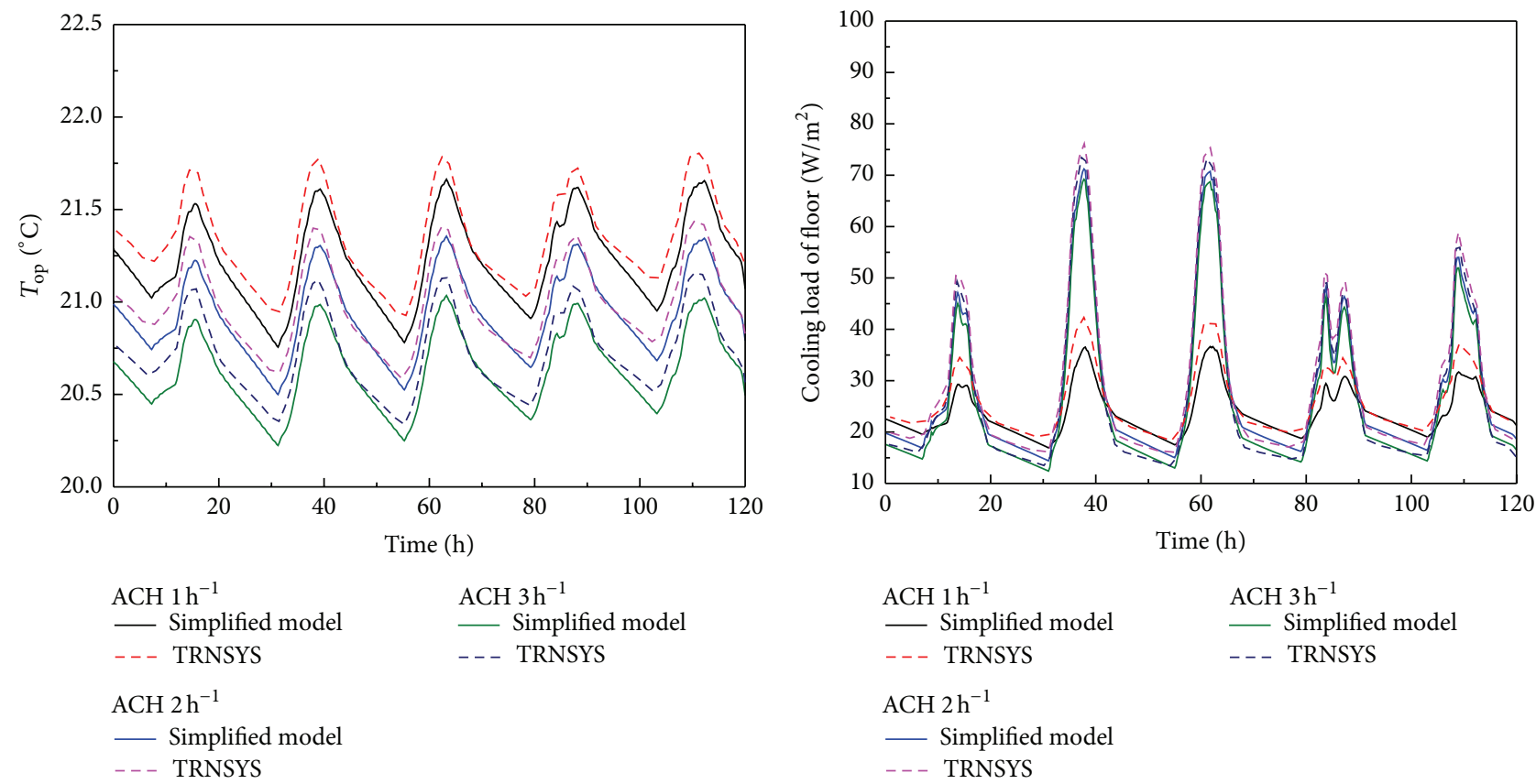

(a) Operative temperature

(b) Cooling load of floor
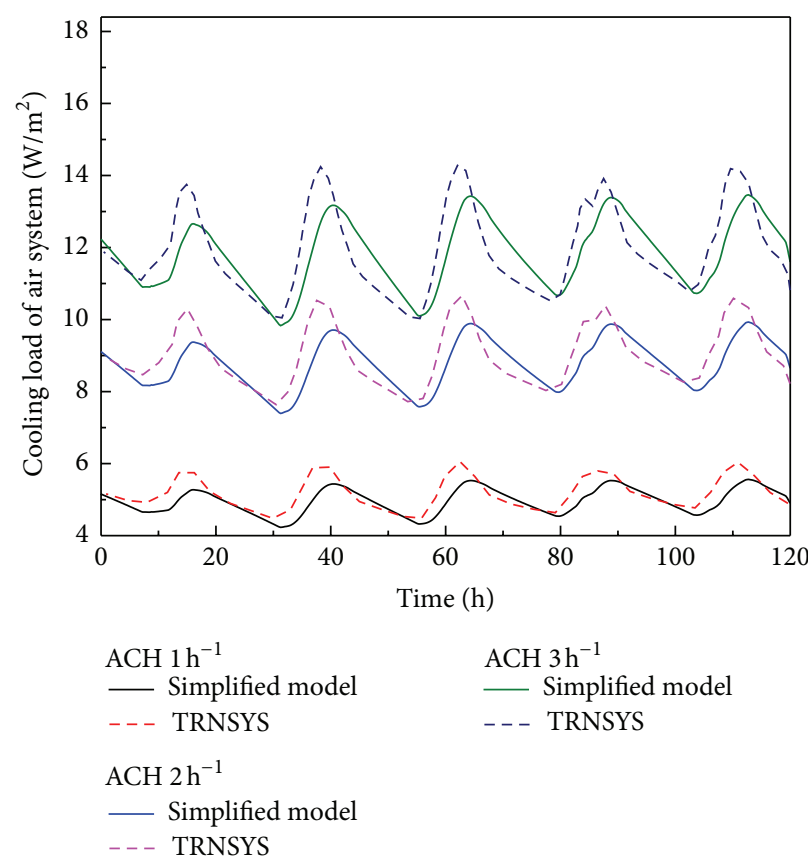

(c) Cooling load of ventilation system

FIGURE 11: Results of simplified model and TRNSYS with various $\mathrm{ACH}\left(T_{\mathrm{fr}}=19^{\circ} \mathrm{C}\right.$ and $\left.T_{s}=18^{\circ} \mathrm{C}\right)$.

According to Figures 10-12, the results of the simplified model under various conditions are consistent with those calculated by TRNSYS. It shows that the model parameters derived from the identification method are good for the simulation case.

In order to further investigate the deviation of operative temperature, cooling load of floor, and ventilation system, Figure 13 shows the results of these three parameters (in Figure 10) in detail. Apparently, the deviations of operative temperature and cooling load of floor and ventilation system change with time periodically and the values reach the maximum at noon. That is because the black-box model of incident solar radiation is unfaithful when the solar radiation is too large. Therefore, the deviation can be reduced through improving the incident solar radiation model.

The CV values of the results in Figures 10-12 are listed in Table 3, and the adaptability of simplified model for various control parameters can be compared. It is very clear that the 

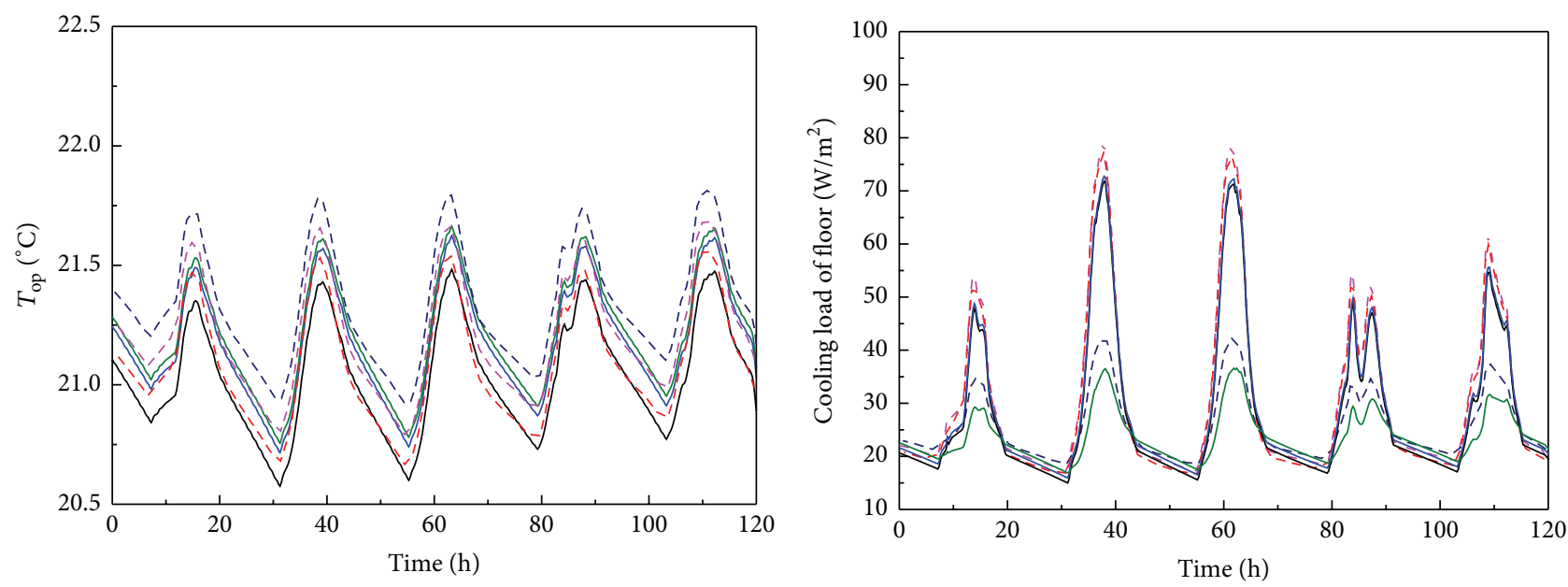

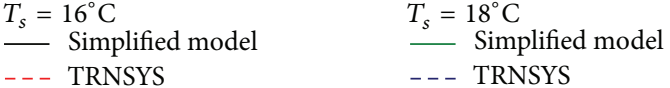

$$
\begin{aligned}
& T_{s}=17^{\circ} \mathrm{C}
\end{aligned}
$$

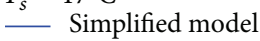

$$
\begin{aligned}
& \text { _. - TRNSYS }
\end{aligned}
$$

(a) Operative temperature

$$
\begin{aligned}
& T_{s}=16^{\circ} \mathrm{C} \\
& \text { S Simplified model } \\
& \text {-. - TRNSYS } \\
& T_{s}=18^{\circ} \mathrm{C} \\
& \text { Simplified model } \\
& T_{s}=17^{\circ} \mathrm{C} \\
& \text { - Simplified model } \\
& \text { _. - TRNSYS }
\end{aligned}
$$

(b) Cooling load of floor

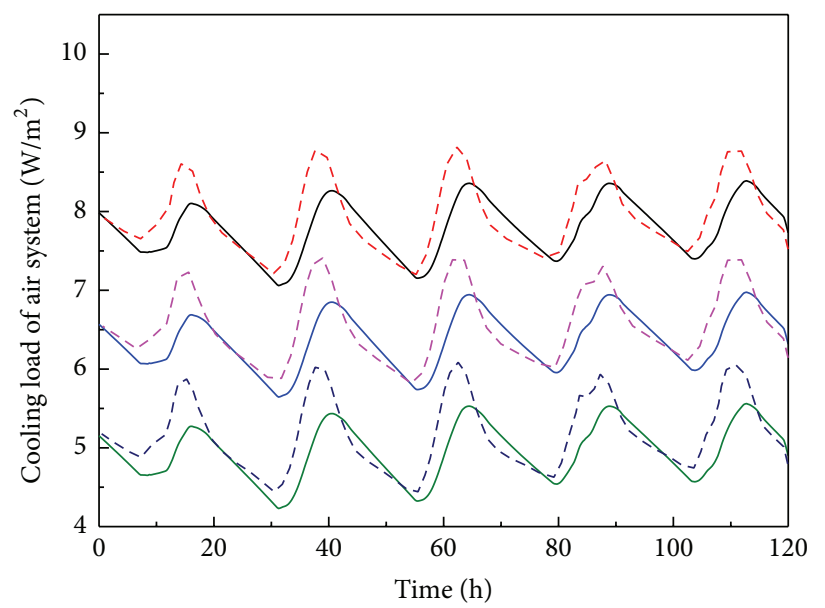

$$
\begin{aligned}
& T_{s}=16^{\circ} \mathrm{C} \\
& -\quad \text { Simplified model } \\
& --- \text { TRNSYS } \\
& T_{s}=17^{\circ} \mathrm{C} \\
& - \text { Simplified model } \\
& --- \text { TRNSYS }
\end{aligned}
$$$$
T_{s}=18^{\circ} \mathrm{C}
$$$$
\text { - Simplified model }
$$

(c) Cooling load of ventilation system

FIGURE 12: Results of simplified model and TRNSYS with various $T_{s}\left(T_{\mathrm{fr}}=19^{\circ} \mathrm{C}\right.$ and $\left.\mathrm{ACH}=1\right)$

TABLE 3: CV values of operative temperature and cooling load.

\begin{tabular}{lccc}
\hline & Figure 10 & Figure 11 & Figure 12 \\
\hline$T_{\text {op }}$ & $0.63 \%$ & $0.52 \%$ & $0.46 \%$ \\
Cooling load of floor & $11.93 \%$ & $9.59 \%$ & $9.61 \%$ \\
Cooling load of ventilation system & $5.66 \%$ & $7.07 \%$ & $5.35 \%$ \\
\hline
\end{tabular}




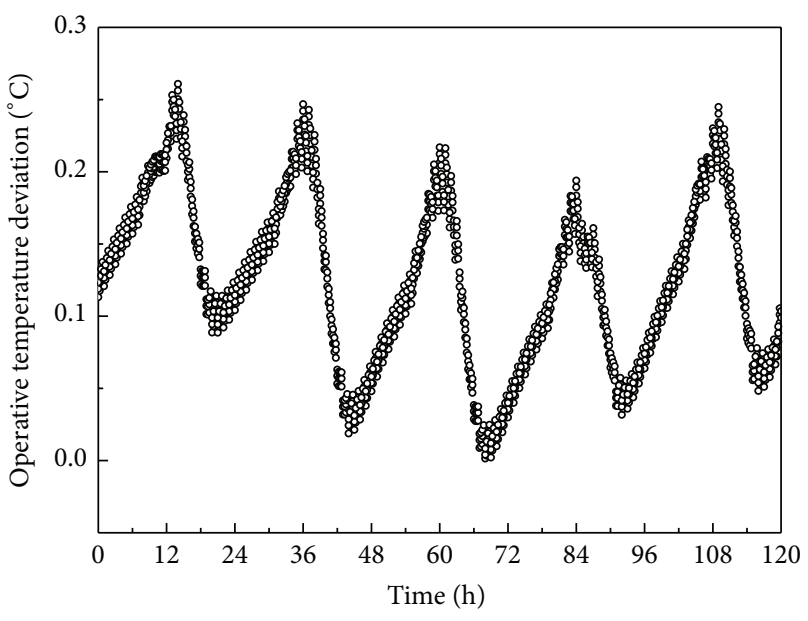

(a) Operative temperature

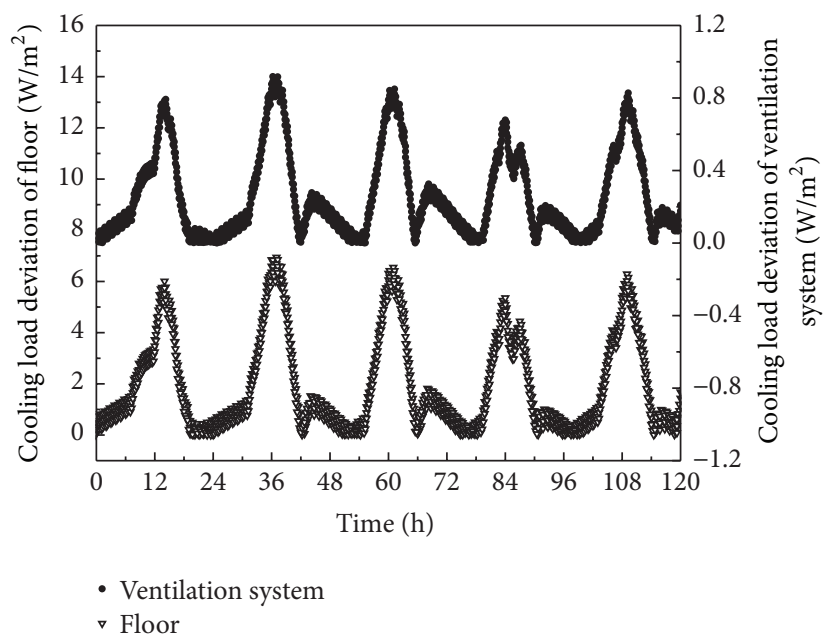

(b) Cooling load

FIGURE 13: Deviation of simplified model and TRNSYS.

$\mathrm{CV}$ values of $T_{\text {op }}$ under all conditions are smaller than those of both floor system cooling load and air system cooling load. All the $\mathrm{CV}$ values of $T_{\text {op }}$ are below $1 \%$. By contrast, the CV values for floor cooling load (about 12\%) are larger than those of both operative temperature and air system cooling load.

The incident solar radiation is the most important factor for the floor cooling load, and the values in the second and the third days are greater than those in other days (as depicted in Figure 9). Accordingly, it is clear that the cooling loads in the second and the third days are larger than those in other days (Figures 10(b), 11(b), and 12(b)). Since there are prediction errors in the solar radiation heat gains for the envelope surfaces, the error of floor cooling load is larger than the cooling load of ventilation system. Besides, an accurate prediction of the indoor temperature is beneficial to avoid the condensation, which is an important control mission for radiant cooling systems. Although there is a larger prediction error in cooling loads, the prediction of operative temperature is accurate. Therefore, the simplified model is sufficient for MPC in buildings with radiant systems.

\section{Conclusions}

In the building with radiant cooling, on one hand, the radiant surface induces long wave radiant heat exchange between the cooling surface and other surfaces. On the other hand, the incident solar radiation on the cooling surface through the window is absorbed directly. Both the long wave radiation and the incident solar radiation are the dominant influencing factors for the cooling capacity of the radiant surface. Therefore, it is important to accurately calculate the above two factors for the prediction model of MPC. In this paper, the semiempirical model and black-box model are adopted with RC model to construct the prediction model for the building with radiant terminals. The RC model is used for modeling the heat transfer of building envelopes.
The incident solar radiation is forecasted by the black-box model and the long wave radiant heat exchange is forecasted by the semiempirical model. In order to accurately predict the indoor environment and cooling load, the genetic algorithm is employed to identify the model parameters.

The reference model and identification method are tested with TRNSYS. The testing results show that the reference model is suitable for the simulation case. The $\mathrm{CV}$ values of operative temperature are below $1 \%$ and the $\mathrm{CV}$ values of cooling load are within $12 \%$. The accurate operative temperature is beneficial to avoid the cooling surface condensation. But due to the lower accuracy of black-box model for solar radiation heat gains of envelopes, the predictive accuracy for cooling load of radiant floor is slightly lower. However, the maximum error of prediction value is only about $12 \%$, so the model accuracy is considered to be acceptable for the supervisory control purpose.

Compared with other building simulation tools, the hybrid model in this paper can integrate with other HVAC component models to realize the supervisory control more conveniently. Due to the application of hybrid model, the model complexity has increased. This may smoothly increase the calculation time for the parameter identification. But the model complexity does not have a significant effect on the application of the hybrid model. In the future work, it is necessary to improve the accuracy of the model and to increase the model parameter identification efficiency. Moreover, the radiant terminal model will be built and combined with the simplified building thermal model in this paper to optimize the control of the radiant system.

\section{Symbols}
A: Area $\left(\mathrm{m}^{2}\right)$
c: Thermal capacity $\left(\mathrm{J} \cdot \mathrm{m}^{-2} \cdot \mathrm{K}^{-1}\right)$
$c_{p}$ : Specific heat capacity $\left(\mathrm{J} \cdot \mathrm{kg}^{-1} \cdot \mathrm{K}^{-1}\right)$ 


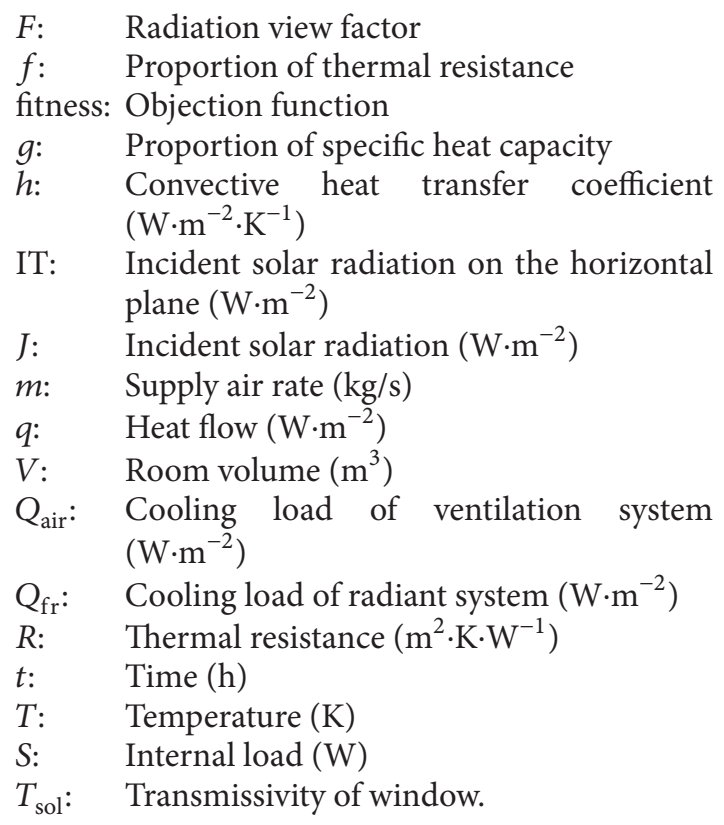

\section{Greek Symbols}

$\varepsilon$ : Emissivity

$\omega$ : Weight factor

$\gamma$ : Absorption coefficient

$\rho$ : Air density $\left(\mathrm{kg} \cdot \mathrm{m}^{-3}\right)$

$\sigma$ : Stefan-Boltzmann constant $\left(\mathrm{W} \cdot \mathrm{m}^{-2} \cdot \mathrm{K}^{-4}\right)$.

\section{Subscripts}

$\begin{array}{ll}\text { rf: } & \text { Roof } \\ \text { fr: } & \text { Floor } \\ \text { wall: } & \text { Wall } \\ \text { win: } & \text { Window } \\ s: & \text { Supply air } \\ \text { air: } & \text { Indoor air } \\ \text { rad: } & \text { Long wave radiation } \\ \text { sol: } & \text { Solar direct radiation } \\ \text { out: } & \text { Outside } \\ l: & \text { Outside node of 3R2C model } \\ o: & \text { Inside node of 3R2C model. }\end{array}$

\section{Conflict of Interests}

The authors declare that there is no conflict of interests regarding the publication of this paper.

\section{Acknowledgments}

The research work is supported by Sichuan Province Youth Science and Technology Innovation Team of Building Environment and Energy Efficiency (no. 2015TD0015).

\section{References}

[1] G. Huang, "Model predictive control of VAV zone thermal systems concerning bi-linearity and gain nonlinearity," Control Engineering Practice, vol. 19, no. 7, pp. 700-710, 2011.
[2] S. Yuan and R. Perez, "Multiple-zone ventilation and temperature control of a single-duct VAV system using model predictive strategy," Energy and Buildings, vol. 38, no. 10, pp. 1248-1261, 2006.

[3] G. P. Henze, D. E. Kalz, S. Liu, and C. Felsmann, "Experimental analysis of model-based predictive optimal control for active and passive building thermal storage inventory," HVAC\&R Research, vol. 11, no. 2, pp. 189-213, 2005.

[4] J. Široký, F. Oldewurtel, J. Í. Cigler, and S. Prívara, “Experimental analysis of model predictive control for an energy efficient building heating system," Applied Energy, vol. 88, no. 9, pp. 3079-3087, 2011.

[5] A. Afram and F. Janabi-Sharifi, "Theory and applications of HVAC control systems-a review of model predictive control (MPC)," Building and Environment, vol. 72, pp. 343-355, 2014.

[6] A. J. Wright, D. Bloomfield, and T. J. Wiltshire, "Review paper: building simulation and building representation: overview of current developments," Building Services Engineering Research \& Technology, vol. 13, no. 1, pp. 1-11, 1992.

[7] Z. Liao and A. L. Dexter, "A simplified physical model for estimating the average air temperature in multi-zone heating systems," Building and Environment, vol. 39, no. 9, pp. 1013-1022, 2004.

[8] S. Wang and Z. Ma, "Supervisory and optimal control of building HVAC systems: a review," HVAC\&R Research, vol. 14, no. 1, pp. 3-32, 2008.

[9] I. Hazyuk, C. Ghiaus, and D. Penhouet, "Optimal temperature control of intermittently heated buildings using Model Predictive Control: part I-building modeling," Building and Environment, vol. 51, pp. 379-387, 2012.

[10] J. A. Crabb, N. Murdoch, and J. M. Penman, "A simplified thermal response model," Building Services Engineering Research \& Technology, vol. 1, pp. 13-19, 1987.

[11] T. Dewson, B. Day, and A. D. Irving, "Least squares parameter estimation of a reduced order thermal model of an experimental building," Building and Environment, vol. 28, no. 2, pp. 127-137, 1993.

[12] M. M. Gouda, S. Danaher, and C. P. Underwood, "Building thermal model reduction using nonlinear constrained optimization," Building and Environment, vol. 37, no. 12, pp. 12551265, 2002.

[13] S. Wang and X. Xu, "Simplified building model for transient thermal performance estimation using GA-based parameter identification," International Journal of Thermal Sciences, vol. 45, no. 4, pp. 419-432, 2006.

[14] X. Xu and S. Wang, "Optimal simplified thermal models of building envelope based on frequency domain regression using genetic algorithm," Energy and Buildings, vol. 39, no. 5, pp. 525536, 2007.

[15] A. P. Ramallo-González, M. E. Eames, and D. A. Coley, "Lumped parameter models for building thermal modelling: an analytic approach to simplifying complex multi-layered constructions," Energy and Buildings, vol. 60, pp. 174-184, 2013.

[16] G. Fraisse, C. Viardot, O. Lafabrie, and G. Achard, "Development of a simplified and accurate building model based on electrical analogy," Energy and Buildings, vol. 34, no. 10, pp. 10171031, 2002.

[17] Z. O’Neill, S. Narayanan, and A. R. Brahme, "Model-based thermal load estimation in buildings," in Proceedings of the 4th National Conference of IBPSA-USA (SimBuild '10), pp. 474-481, New York, NY, USA, August 2010. 
[18] UIUCLBNL, EnergyPlus Engineering Reference: The Reference to EnergyPlus Calculations, U.S. Department of Energy, 2005.

[19] A. Nassiopoulos, R. Kuate, and F. Bourquin, "Calibration of building thermal models using an optimal control approach," Energy and Buildings, vol. 76, pp. 81-91, 2014.

[20] M. Wetter and P. Haves, "A Modular building controls virtual test Bed for the Inte-gration of heterogeneous systems," in Proceedings of the 3rd Nation Conference of IBPSA-USA SimBuild, Berkeley, Calif, USA, August 2008.

[21] X. Li and J. Wen, "Building energy consumption on-line forecasting using physics based system identification," Energy and Buildings, vol. 82, pp. 1-12, 2014.

[22] S. Royer, S. Thil, T. Talbert, and M. Polit, "A procedure for modeling buildings and their thermal zones using co-simulation and system identification," Energy and Buildings, vol. 78, pp. 231-237, 2014.

[23] G. N. Walton, "A new algorithm for radiant interchange in room load calculations," ASHRAE Transactions, vol. 86, pp. 190-208, 1980.

[24] A. Odyjas and A. Górka, "Simulations of floor cooling system capacity," Applied Thermal Engineering, vol. 51, no. 1-2, pp. 8490, 2013.

[25] Y. Zhao, Air Conditioning, China Architecture \& Building Press, Beijing, China, 2009 (Chinese).

[26] J. A. Duffie and W. A. Beckman, Solar Engineering of Thermal Processes, John Wiley \& Sons, Hoboken, NJ, USA, 2013.

[27] A. Kusiak, Y. Zeng, and G. Xu, "Minimizing energy consumption of an air handling unit with a computational intelligence approach," Energy and Buildings, vol. 60, pp. 355-363, 2013.

[28] S. A. Kalogirou, "Artificial neural networks and genetic algorithms in energy applications in buildings," Advances in Building Energy Research, vol. 3, no. 1, pp. 83-120, 2009.

[29] CEN, "Energy performance of buildings—sensible room cooling load calculation-general criteria and validation procedures," EN ISO 15255, CEN, 2007.

[30] J. Francis and R. E. Edwards, "Speedy comfort assessment using ISO 7730," Building Services Engineering Research \& Technology, vol. 16, no. 3, pp. 165-168, 1995.

[31] ASHRAE, ASHRAE Applications Handbook, American Society of Heating, Refrigeration and Air-Conditioning Engineering, Atlanta, Ga, USA, 1999. 


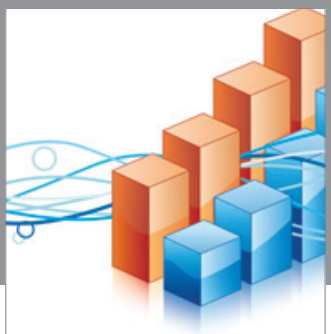

Advances in

Operations Research

vatem alat4

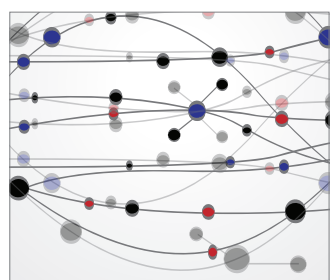

\section{The Scientific} World Journal
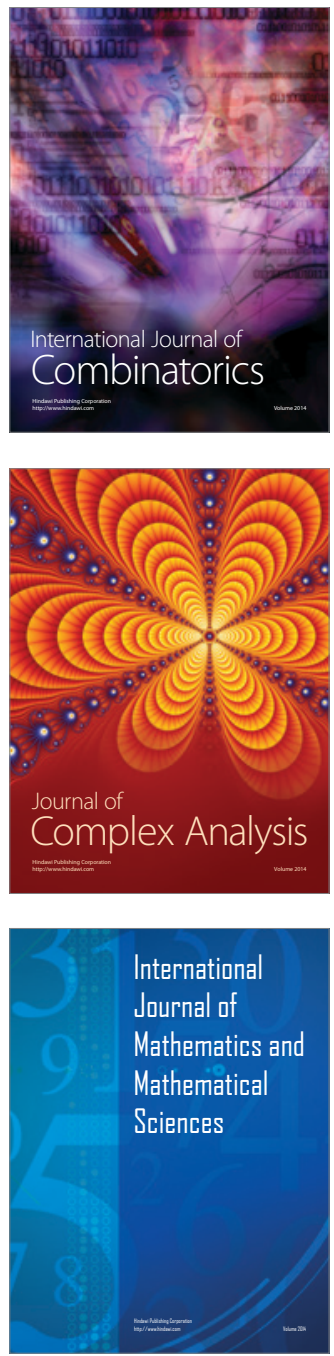
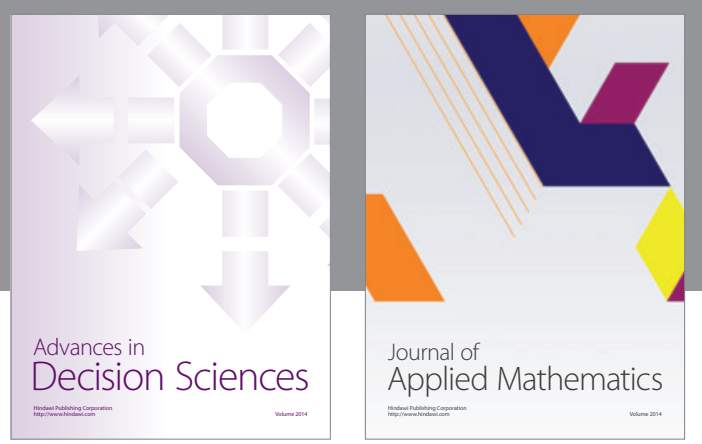

Algebra

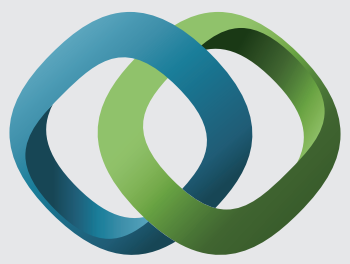

\section{Hindawi}

Submit your manuscripts at

http://www.hindawi.com
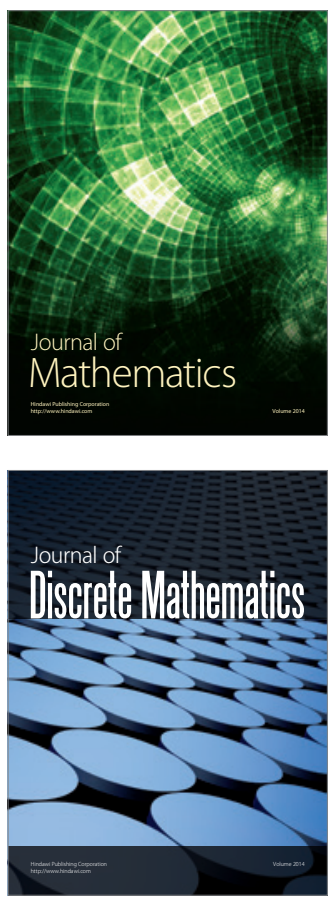

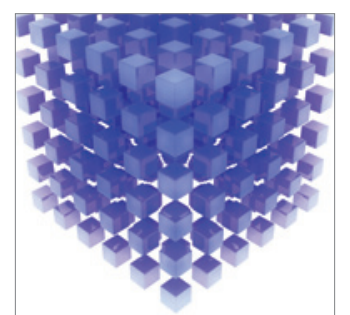

Mathematical Problems in Engineering
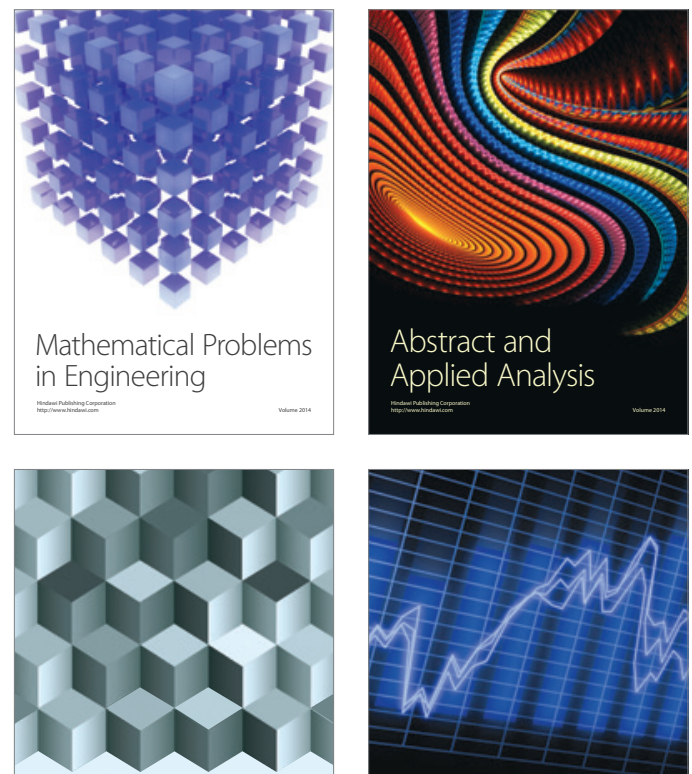

Journal of

Function Spaces

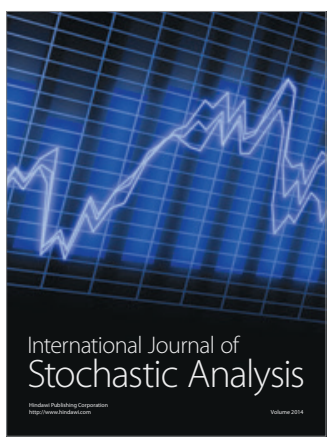

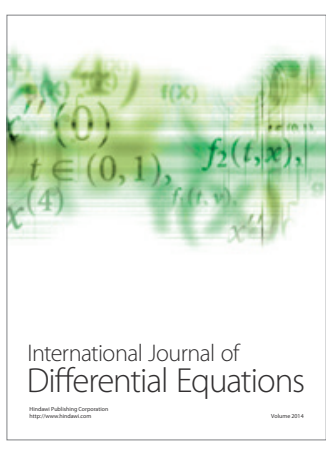
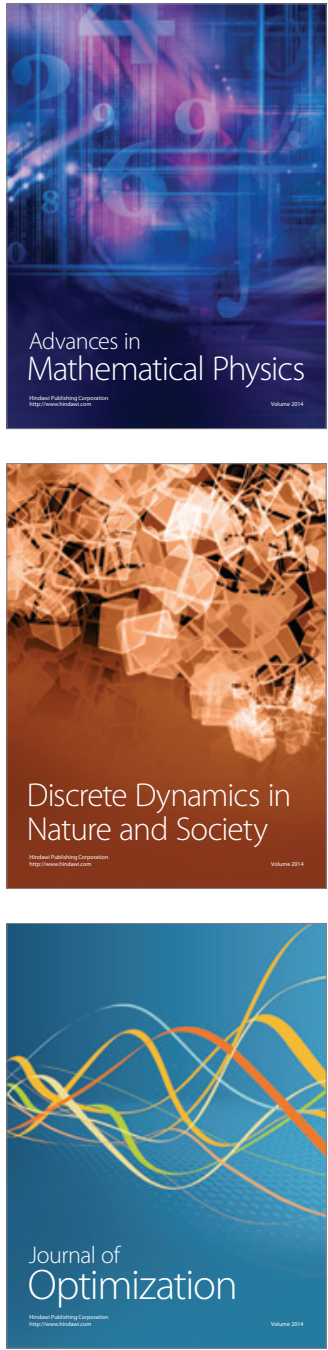